\title{
PENGARUH PESTISIDA NABATI DAN KIMIA TERHADAP MORTALITAS Lepidiota stigma Fabricius (Coleoptera: Scarabaeidae) PADA TANAMAN TEBU
}

\author{
Effect of Botanical Pesticides and Chemical Pesticides on Sugar Cane Plant \\ Lepidiota stigma (Coleoptera: Scarabaeidae)
}

\author{
Eko Siswanto $^{1)}$, Etik M. Achadian ${ }^{2)}$, dan Tri Kurniastuti1) \\ 1) Program Studi Agroteknologi, Fakultas Pertanian, Universitas Islam Balitar \\ 2) Pusat Penelitian Perkebunan Gula Indonesia (P3GI) Pasuruan \\ Email : ${ }^{* 1)}$ ekosiswantolaskar96@ gmail.com,${ }^{2)}$ etik.achadian@ gmail.com , \\ ${ }^{3}$ kurniastuti5@gmail.com
}

\begin{abstract}
ABSTRAK
Penelitian ini dilakukan untuk mengetahui pengaruh perilaku Lepidoptera stigma Fabricius dan hasil beberapa perlakuan kontrol terhadap kematian L. Stigma. Pengujian L. stigma dilakukan dalam 2 tahap, pengujian langsung dan pengujian tidak langsung. Perlakuan disusun menggunakan rancangan acak kelompok (RAK) 4 perlakuan (kontrol, limbah kulit kacang mete dengan dosis $600 \mathrm{~kg} / \mathrm{ha}$, limbah tembakau $250 \mathrm{~kg} / \mathrm{ha}$, dan insektisida imidacloprid dengan dosis $7,5 \mathrm{~kg} / \mathrm{ha}$ ) diulang 4 kali. Variabel yang diamati termasuk aktivitas antifeedant, mortalitas dan peringkat gejala kerusakan tanaman. Hasil penelitian menunjukkan bahwa perlakuan menggunakan imidacloprid 7,5 kg / ha menunjukkan hasil terbaik pada variabel pengamatan aktivitas antifeedant, mortalitas L. stigma, dan peringkat gejala kerusakan tanaman.
\end{abstract}

Kata kunci : L. stigma, Aktiviatas Antifeedan, Mortalitas, gejala kerusakan tanaman

\section{ABSTRACT}

This research was conducted to determine the effect of $L$. Stigmafeeding behavior and the results of several control treatments on L.Stigma. mortality. Treatment of L. stigma testing was carried out in 2 stages, direct testing and indirect testing. The treatments were arranged using a randomized block design (RBD) 4 treatments (control, cashew nut shell waste at a dose of $600 \mathrm{~kg} / \mathrm{ha}$, tobacco waste $250 \mathrm{~kg} / \mathrm{ha}$, and imidacloprid insecticide at a dose of 7.5 $\mathrm{kg} / \mathrm{ha}$ ) were repeated 4 times. Variables observed included antifeedant activity, mortality and plant damage symptom ratings. The results showed that the treatment using imidacloprid 7.5 $\mathrm{kg} / \mathrm{ha}$ showed the best results on the parameters of observing antifeedant activity, L. stigma mortality, and symptom rating of plant damage.

Keywords : L. stigma, Antifeedant Activity, Mortality, Symptom ratings of plant damage

\section{PENDAHULUAN}

Tebu (Saccharum officinarum. L) merupakan salah satu komoditi yang banyak ditanam di Indonesia sebagai bahan baku dalam pembuatan gula. Pada tahun 2013-2015 produksi gula nasional berturut-turut mencapai 2,6 juta ton (Anonim, 2014), 2,57 dan 2,49 juta ton (Nugraha, 2016). Seiring dengan adanya peningkatan jumlah penduduk di Indonesia, mempengaruhi kebutuhan gula sehingga produksi tebu perlu ditingkatkan. Kebutuhan gula nasional rata-rata yang harus dipenuhi untuk kebutuhan industri dan rumah tangga adalah 2,82 juta ton per tahun. Hingga saat ini peningkatan permintaan gula, belum diimbangi 
dengan peningkatan produksi gula secara nasional. Permasalahan industri gula yang dihadapi saat ini adalah menurunnya produktivitas tanaman tebu, salah satunya disebabkan oleh hama tebu yaitu Lepidiota stigma Fabricius (Ditjenbun, 2011). Dalam penelitiannya, Aprilia (2011) mengemukakan bahwa hama tebu L. stigma mempunyai daerah sebaran cukup luas, yang meliputi daerah tropika sampai daerah yang beriklim sedang Eucblora viridisumum, terutama di daerah pegunungan.

L. stigma menyerang tanaman tebu terutama pada lahan kering serta dapat berpotensi menurunkan hasil panen hingga $50 \%$ (Setyaningsih, 2010). Sedangkan untuk batas ambang ekonomi larva L. stigma adalah apabila terdapat 4-5 ekor per rumpun tanaman tebu. L. stigma instar satu memakan bagian perakaran tanaman yang masih lunak, akan tetapi gejala kerusakan yang ditimbulkan tidak begitu berarti. Pada vase instar ketiga jumlah makan yang diperlukan L. stigma semakin banyak sehingga kerusakan yang ditimbulkan semakin besar (Saragih, 2009).

L. stigma dapat dikendalikan menggunakan insektisida berbahan aktif imidakloprid. Insektisida imidakloprid termasuk dalam kelompok neonikotinoid yang memiliki efek translaminar (memiliki kemampuan menembus jaringan pada akar maupun daun), memiliki kemampuan sebagai racun kontak dan lambung, serta memiliki kemampuan bekerja secara sistemik. Sehingga sangat efektif untuk mengendalikan jenis hama yang merusak tanaman dengan cara menghisap maupun menusuk. Bahan aktif yang terkandung dalam insektisida imidakloprid tidak membahayakan mamalia karena imidakloprid mampu mengikatlebih kuat pada reseptor neuron serangga dibandingkan reseptor neuron pada mamalia, sehingga imidakloprid lebih beracun bagi serangga daripada mamalia. Imidakloprid merupakan salah satu bahan aktif yang paling banyak digunakan petani di Indonesia untuk mengendalikan hama pada tanaman, serta merupakan insektisida berbahan aktif yang termasuk ke dalam kelompok neonikotinoid dari sub kelompok kloronikotinil. Insektisida imidakloprid mempunyai sistem kerja secara sistemik untuk mengendalikan hama tanaman sejenis wereng coklat. Sementara itu bahan aktif Buprofezin banyak dijumpai di pasaran dengan nama dagang Ruprosida, Applaud, Lugen dan Lauda. Efektifitas imidakloprid mampu menekan serta menghambat pergantian kulit pada hama wereng coklat (Trubus, 2010).

Pengendalian hama L. stigma juga dapat dilakukan dengan memanfaatkan bagian tanaman sebagai pestisida nabati. Dalam bagian tumbuhan terdapat bahan kimia sebagai bioaktivasi terhadap serangga yaitu sebagai bahan penolak makan (repellent), penghambat aktivitas makan (antifeedant), penghambat perkembangan serangga (insect growth regulator), dan penghambat penularan (oviposition deterrent) (Sudarmo, 2005).

Tanaman mete merupakan jenis tanaman yang dapat dimanfaatkan sebagai pestisida nabati. Pestisida nabati biji mete mengandung azadirakhtin, meliantriol, salannin (Lestari et $a l$, 2013).Senyawa aktif yang terdapat pada tanaman jambu mete tidak membunuh hama secara tepat, tetapi berpengaruh terhadap daya makan, menghambat perkembangbiakan, menghambat pertumbuhan, penurunan daya tetas telur dan daya reproduksi, menekan proses ganti kulit, berperan sebagai pemandul, serta mampu menghambat pembentukan kitin. Pada tanaman jambu mete terdapat kandungan minyak biji jambu mete yang mengandung senyawa fenol. Senyawa fenol merupakan senyawa gabungan antara senyawa gabungan antara asam 
anacardic (90\%) dan kardol (100\%). Senyawa fenol dapat digunakan sebagai insektisida untuk mengendalikan hama rayap (Asogwa et al., 2007).

Tujuan dari penelitian ini: Mengetahui pengaruh perilaku makan (antifeedant activity) L.stigma, , mortalitas L. stigma, tingkat gejala kerusakan tanaman setelah dilakukan beberapa perlakuan pengendalian

\section{METODE PENELITIAN}

Kegiatan penelitian dilaksanakan selama tiga bulan yaitu bulan April sampai dengan Juni 2019 di Rumah Kaca dan Laboratorium Hama Pusat Penelitian Perkebunan Gula Indonesia (P3GI) Pasuruan

Alat yang digunakan dalam penelitian ini meliputi; cawan petri, tabung reaksi, pipet 200-1000 $\mu$ l (Socorex), tabung Erlenmeyer, sprayer mini, haemocytometer, sekop kecil, pinset, spatula mikroskop, gelas beker, batang pengaduk, kantong plastik ( 1 dan $0,5 \mathrm{~kg}$ ), pipa PVC (diameter $3 \mathrm{~cm}$ ), ember, bak seng, stoples plastik, timbangan analitik, $\mathrm{pH}$ meter, plastik

wrap, alumunium foil, kapas dan kamera. Sedangkan bahan yang digunakan yaitu larva uret L. stigma instar 2 dan 3, cacahan batang tebu, tanah steril, air steril, alkohol 70\%, insektisida imidakloprid dengan merek dagang Suscon maxi 20 G, limbah kulit jambu mete dengan merek dagang Metaganik, dan limbah tembakau.

Perlakuan disusun menggunakan rancangan acak kelompok (RAK) 4 perlakuan diulang sebanyak 4 kali. Terdapat 4 perlakuan yang digunakan yaitu kontrol, limbah kulit biji mete dosis $600 \mathrm{~kg} / \mathrm{ha}$, limbah tembakau dosis $250 \mathrm{~kg} / \mathrm{ha}$, dan insektisida imidakloprid dosis $7,5 \mathrm{~kg} / \mathrm{ha}$. Terdapat dua perlakuan pengujian yang digunakan dalam penelitian ini yaitu pengujian secara langsung dan pengujian secara tidak langsung.

Analisis data pengendalian setiap pengujian (pestisida nabati, insektisida sistemik dan pengujian perilaku L.stigma) dilakukan dengan menggunakan analisis sidik ragam (two way analysis of varians). Apabila terdapat perbedaan maka dilakukan uji Duncan Multiple Range Test (DRMT) pada taraf kesalahan 5\%.

Variabel Pengamatan : (a) Pengujian secara langsung: variabel yang diamati meliputi aktivitas antifeedant, mortalitas, dan rating gejala kerusakan tanaman. (b) Pengujian secara tidak langsung: variabel yang diamati meliputi mortalitas, dan rating gejala kerusakan tanaman.

\section{HASIL DAN PEMBAHASAN}

\section{Pengaruh Pemberian Pestisida Nabati Terhadap Aktivitas Antifeedant L. stigma}

Berdasarkan hasil analisis sidik ragam (Anova) pada taraf 5\% menunjukkan bahwa pemberian pestisida nabati limbah kulit biji mete yang ditaburkan di sekitar tanaman uji tidak berpengaruh nyata terhadap aktivitas antifeedant L. stigma pada pengamatan (2 HSA, 4 HSA, 8 HSA, 12 HSA, dan 14 HSA). Namun pemberian pestisida nabati limbah kulit biji mete yang ditaburkan di sekitar tanaman uji berpengaruh nyata terhadap aktivitas antifeedant $L$. stigma pada 6 HSA dan 10 HSA. Data disajikan dalam (Tabel 1)

Tabel 1. Aktivitas antifeedant L. stigma terhadap perlakuan pestisida nabati. 


\begin{tabular}{|c|c|c|c|c|c|c|c|c|c|c|}
\hline \multirow[t]{2}{*}{ Perlakuan } & \multicolumn{10}{|c|}{ Aktivitas antifeadant } \\
\hline & 2 HSA & & 4 HSA & & 6 HSA & 8 HSA & & $10 \mathrm{HSA}$ & 12 HSA & $14 \mathrm{HSA}$ \\
\hline Kontrol & 36.00 & $\mathrm{a}$ & 29.91 & $\mathrm{a}$ & $34.42 \mathrm{ab}$ & 40.53 & $\mathrm{a}$ & $26.87 \mathrm{a}$ & $32.47 \mathrm{a}$ & $34.78 \mathrm{a}$ \\
\hline $\begin{array}{l}\text { LKB Mete } \\
600 \mathrm{~kg} / \mathrm{ha}\end{array}$ & 51.46 & $\mathrm{a}$ & 47.01 & $\mathrm{a}$ & $33.63 \mathrm{ab}$ & 29.70 & $\mathrm{a}$ & $27.93 \mathrm{ab}$ & $25.98 \mathrm{a}$ & 30.25 a \\
\hline $\begin{array}{l}\text { Lb.Tembaka } \\
\text { u } 250 \mathrm{~kg} / \mathrm{ha}\end{array}$ & 50.68 & $\mathrm{a}$ & 37.03 & $\mathrm{a}$ & 29.40 a & 30.77 & a & $19.03 \mathrm{a}$ & 28.80 a & $31.22 \mathrm{a}$ \\
\hline $\begin{array}{l}\text { Imidakloprid } \\
7,5 \mathrm{~kg} / \mathrm{ha}\end{array}$ & 43.83 & $\mathrm{a}$ & 37.55 & $\mathrm{a}$ & $46.83 \mathrm{~b}$ & 45.45 & $\mathrm{a}$ & $36.72 \mathrm{~b}$ & $32.32 \mathrm{a}$ & $36.68 \mathrm{a}$ \\
\hline
\end{tabular}

Tabel 1 menunjukkan bahwa perlakuan pemberian pestisida nabati limbah kulit biji mete tidak berpengaruh nyata terhadap aktivitas antifeedant L. stigma pada (2 HSA, 4 HSA, 8 HSA, 12 HSA, dan 14 HSA). Walaupun tidak berpengaruh nyata pemberian pestisida nabati limbah kulit biji mete dengan dosis $600 \mathrm{~kg} / \mathrm{ha}$ mempunyai potensi yang lebih baik daripada perlakuan menggunakan pestisida nabati limbah tembakau dosis $250 \mathrm{~kg} / \mathrm{ha}$ pada (2 HSA, 4 HSA, 6 HSA, dan 10 HSA), serta perlakuan menggunakan imidakloprid pada 2 HSA dan 4 HSA. Sedangkan pada pengamatan (6 HSA, 8 HSA, 10 HSA, 12 HSA, dan 14 HSA) perlakuan menggunakan imidakloprid mampu menekan aktivitas makan L. stigma dengan menghasilkan perlakuan terbaik dari perlakuan pestisida nabati limbah kulit biji mete dan pestisida nabati limbah tembakau.Dalam penelitian yang dilakukan Listiyanti et al.,(2012) menyatakan bahwa dalam limbah tembakau terdapat kandungan bahan kimia yang menunjukkan bioaktivitas pada serangga. Bioaktivitas ini berfungsi sebagai bahan penolak makan (repellen), penghambat makan (antifeedant), penghambat penularan (oviposition deterient), dan penghambat seranggan serangga (insect growth regulator), tetapi jarang menyebabkan kematian pada hama tertentu.

Limbah kulit biji mete (A. occidentale)mengandung asam anakardat yang bersifat menolak aktivitas makan (repellent) dan senyawa antiffedant bagi serangga (Muzayyinah, 2010). Perubahan perilaku L. stigma setelah pemberian pestisida nabati diduga disebabkan karena pemberian pestisida nabati yang memiliki zat yang tidak disukai oleh L. stigma. Pada beberapa senyawa fenol memiliki fungsi sebagai antiffedant (penolak makan) serangga, namun juga dapat berperan sebagai penstimuli makan pada serangga lain (Yunita et al., 2009).

\section{Mortalitas L. stigma (Pengujian Secara Langsung)}

Berdasarkan hasil analisis sidik ragam (Anova) pada pengujian secara langsung menunjukkan bahwa pemberian pestisida nabati yang ditaburkan disekitar tanaman uji tidak berpengaruh nyata terhadap mortalitas L. stigma pada pengamatan (3 HSA, 6 HSA, 9 HSA, dan 12 HSA). Pemberian perlakuan pestisida nabati limbah kulit biji mete dengan dosis 600 $\mathrm{kg} / \mathrm{ha}$ yang ditaburkan di sekitar tanaman uji tidak berpengaruh nyata terhadap mortalitas $L$. stigma pada (3 HSA, 6 HSA, 9 HSA, dan 12 HSA). Namun pemberian pestisida nabati 
limbah kulit biji mete berpengaruh nyata terhadap mortalitas L. stigma pada 15 HSA.Data disajikan dalam (Tabel 2)

Tabel 2. Persentase mortalitas L. stigma pada tahapan pengujian secara langsung

\begin{tabular}{|c|c|c|c|c|c|c|}
\hline \multirow{2}{*}{ Perlakuan } & \multicolumn{6}{|c|}{ Mortalitas L. stigma } \\
\hline & 3 HAS & 6 HAS & 9 HSA & & 12 HSA & 15 HSA \\
\hline Kontrol & $0.00 \quad \mathrm{a}$ & $0.00 \mathrm{a}$ & 0.00 & $\mathrm{a}$ & 0.00 & $0.00 \mathrm{a}$ \\
\hline LKB Mete $600 \mathrm{~kg} / \mathrm{ha}$ & $0.00 \quad \mathrm{a}$ & $0.125 \mathrm{a}$ & 0.187 & $\mathrm{a}$ & $0.312 \mathrm{a}$ & $1.60 \mathrm{a}$ \\
\hline L. Tembakau $250 \mathrm{~kg} / \mathrm{ha}$ & $0.625 \mathrm{a}$ & $0.125 \mathrm{a}$ & 0.187 & $\mathrm{a}$ & $0.312 \mathrm{a}$ & $1.80 \mathrm{a}$ \\
\hline Imidakloprid 7,5 kg/ha & $0.125 \mathrm{a}$ & $0.25 \mathrm{a}$ & 0.312 & $\mathrm{a}$ & $0.437 \quad \mathrm{a}$ & $1.80 \mathrm{a}$ \\
\hline
\end{tabular}

Keterangan: Data telah ditransformasi dengan Archin $\sqrt{x+0,5}$ untuk keperluan analisis data statistik. Angka yang diikuti huruf yang sama pada kolom yang sama menunjukkan tidak berbeda nyata pada uji DRMT dengan taraf kesalahan 5\%; HSA: Hari Setelah Aplikasi; LKB: Limbah Kulit Biji, Lb: Limbah.

Hasil analisis ragam (Tabel 2) diatas menunjukkan bahwa perlakuan menggunakan pestisida nabati limbah kulit biji mete tidak berpengaruh nyata terhadap mortalitas L. stigma pada (3 HSA, 6 HSA, 9 HSA, 12 HSA, dan 15 HSA). Walaupun tidak berpengaruh nyata perlakuan pestisida nabati limbah kulit biji mete dengan dosis $600 \mathrm{~kg} / \mathrm{ha}$ mempunyai potensi sama baik dengan perlakuan pemberian pestisida nabati limbah tembakau pada (6 HSA, 9 HSA dan 12 HSA). Sedangkan pada pengamatan (6 HSA, 9HSA, dan 12 HSA) perlakuan menggunakan imidakloprid memberikan hasil mortalitas tertinggi dibandingkan dengan perlakuan lainnya, meskipun tidak berbeda nyata dengan perlakuan menggunakan limbah tembakau pada 15 HSA.

\section{Mortalitas L. stigma (Pengujian Secara Tidak Langsung)}

Berdasarkan hasil analisis ragam (Anova) pada pengujian secara tidak langsung menunjukkan bahwa pemberian pestisida nabati yang ditabur disekitar tanaman uji tidak berpengaruh nyata terhadap mortalitas L. stigma pada (2 HSA, 4 HSA, dan 6 HSA). Pemberian pestisida nabati limbah kulit biji mete yang ditaburkan di sekitar tanaman uji tidak berpengaruh nyata terhadap mortalitas L. stigma pada (2 HSA, 4 HSA, 6 HSA dan 14 HSA), namun berpengaruh nyata pada (8 HSA, $10 \mathrm{HSA}$, dan $12 \mathrm{HSA}$ ). Walaupun tidak berpengaruh nyata perlakuan menggunakan limbah kulit biji mete mempunyai potensi yang lebih baik daripada perlakuan menggunakan imidakloprid pada (2 HSA, 4 HSA, dan 6 HSA) dan perlakuan pestisida nabati limbah tembakau pada (2 HSA, 4 HSA, 6 HSA, 8 HSA, 10 HSA, 12 HSA, dan 14 HSA). Data disajikan dalam (Tabel 3).

Dari hasil analisis ragam (Tabel 3) diatas menunjukkan bahwa perlakuan menggunakan pestisida nabati limbah tembakau yang ditaburkan disekitar tanaman uji tidak berpengaruh nyata terhadap mortalitas L. stigma pada (2 HSA, 4 HSA, 6 HSA, 10 HSA, 12 HSA, dan 14 HSA) namun berpengaruh nyata terhadap mortalitas L. stigma pada 10 HSA. Sementara itu pemberian perlakuan imidakloprid tidak berpengaruh nyata pada (2 HSA, 4 HSA, dan 6 HSA) namun berpengaruh nyata pada (8 HSA, 10 HSA, 12 HSA, dan 14 HSA). Meskipun demikian perlakuan menggunakan imidakloprid memberikan hasil mortalitas tertinggi dibandingkan dengan perlakuan menggunakan pestisida nabati limbah kulit biji 
mete dan pestisida nabati limbah tembakau.Dalam penelitian yang dilakukan oleh Atmajaya dan Wahyono (2009) menunjukkan bahwa penyemprotan ekstrak kulit biji mete pada bibit jambu mete dengan konsentrasi 20\% dapat menyebabkan kematian pada hama Helopeltis antonii hingga 97\%. Sedangkan pada larva L. stigma mengalami kematian akibat pemberian aplikasi limbah kulit biji mete dengan ciri-ciri yang ditemukan diantaranya; perubahan warna menjadi kecoklatan dan berubah menjadi hitam, lembek, dan berbau.

Tabel 3. Persentase mortalitas L. stigma pada tahapan pengujian secara tidak langsung

\begin{tabular}{|c|c|c|c|c|c|c|c|c|c|}
\hline \multirow[t]{2}{*}{ Perlakuan } & \multicolumn{9}{|c|}{ Mortalitas L. stigma } \\
\hline & 2 HSA & 4 HSA & $6 \mathrm{HS}$ & & 8 HSA & & $10 \mathrm{HSA}$ & $12 \mathrm{HSA}$ & 14 HSA \\
\hline Kontrol & $0.00 \mathrm{a}$ & $0.00 \mathrm{a}$ & 0.00 & $\mathrm{a}$ & 0.00 & $\mathrm{a}$ & $0.00 \mathrm{a}$ & $0.00 \mathrm{a}$ & $0.00 \mathrm{a}$ \\
\hline $\begin{array}{l}\text { LKB Mete } \\
600 \mathrm{~kg} / \mathrm{ha}\end{array}$ & $0.05 \mathrm{a}$ & $0.75 \mathrm{a}$ & 0.125 & $\mathrm{a}$ & 0.125 & $\mathrm{~b}$ & $0.125 \mathrm{ab}$ & $0.125 \mathrm{~b}$ & $0.15 \mathrm{a}$ \\
\hline $\begin{array}{l}\text { L.Tembakau } \\
250 \mathrm{~kg} / \mathrm{ha}\end{array}$ & $0.00 \mathrm{a}$ & $0.025 \mathrm{a}$ & 0.075 & $\mathrm{a}$ & $0.10 \quad \mathrm{a}$ & $\mathrm{ab}$ & $0.10 \mathrm{a}$ & $0.075 \mathrm{a}$ & $0.10 \mathrm{a}$ \\
\hline $\begin{array}{l}\text { Imidakloprid } \\
7,5 \mathrm{~kg} / \mathrm{ha}\end{array}$ & $0.00 \mathrm{a}$ & $0.00 \mathrm{a}$ & 0.10 & $\mathrm{a}$ & 0.175 & $\mathrm{~b}$ & $0.25 \mathrm{~b}$ & $0.325 \mathrm{~b}$ & $0.35 \mathrm{~b}$ \\
\hline
\end{tabular}

Keterangan: Data telah ditransformasi dengan Archin $\sqrt{x+0,5}$ untuk keperluan analisis data statistik. Angka yang diikuti huruf yang sama pada kolom yang sama menunjukkan tidak berbeda nyata pada uji DRMT dengan taraf kesalahan 5\%; HSA: Hari Setelah Aplikasi; LKB: Limbah Kulit Biji, Lb: Limbah.

\section{Tingkat Gejala Kerusakan Tanaman (Pengujian Secara Langsung)}

Berdasarkan hasil analisis ragam (Anova) pada pengujian secara langsung menunjukkan bahwa pemberian pestisida nabati yang ditaburkan disekitar tanaman uji berpengaruh nyata terhadap rating gejala kerusakan tanaman. Pemberian pestisida nabati limbah kulit biji mete berpengaruh nyata terdapat rating gejala kerusakan tanaman pada (3 HSA, 6 HSA, 9 HSA, dan 12 HSA) dan memiliki tingkat kerusakan paling sedikit dari perlakuan menggunakan pestisida nabati limbah tembakau pada (3 HSA, 9 HSA, dan 12 HSA). Meskipun tingkat kerusakan tanaman tergolong paling sedikit, tetapi tidak berbeda nyata pada 15 HSA dengan persentase kerusakan tanaman sebesar 3,56\%.

Tabel 4. Persentase rating gejala kerusakan tanaman pada tahapan pengujian secara langsung

\begin{tabular}{|c|c|c|c|c|c|}
\hline \multirow{2}{*}{ Perlakuan } & \multicolumn{5}{|c|}{ Rating Gejala Kerusakan Tanaman } \\
\hline & 3 HSA & 6 HSA & 9 HSA & 12 HSA & 15 HSA \\
\hline Kontrol & $2.43 \mathrm{~b}$ & $4.06 \mathrm{c}$ & $4.25 \mathrm{c}$ & $4.62 \mathrm{c}$ & $4.93 \mathrm{c}$ \\
\hline LKB Mete $600 \mathrm{~kg} / \mathrm{ha}$ & $1.31 \mathrm{~b}$ & $2.18 \mathrm{~b}$ & $2.56 \mathrm{~b}$ & $3.06 \mathrm{~b}$ & $3.56 \mathrm{~b}$ \\
\hline L. Tembakau $250 \mathrm{~kg} / \mathrm{ha}$ & $1.43 \mathrm{~b}$ & $2.12 \mathrm{~b}$ & $2.93 \mathrm{~b}$ & $3.43 \mathrm{~b}$ & $3.56 \mathrm{~b}$ \\
\hline Imidakloprid 7,5 kg/ha & $0.00 \mathrm{a}$ & $0.00 \mathrm{a}$ & $0.00 \mathrm{a}$ & $0.00 \mathrm{a}$ & $0.00 \mathrm{a}$ \\
\hline
\end{tabular}

Keterangan: Data telah ditransformasi dengan Archin $\sqrt{x+0,5}$ untuk keperluan analisis statistik. Angka yang diikuti huruf yang sama pada kolom yang sama menunjukkan tidak berbeda nyata pada uji DRMT dengan taraf kesalahan 5\%; HSA: Hari Setelah Aplikasi; LKB: Limbah Kulit Biji, Lb: Limbah. 
Hasil persentase rating gejala kerusakan tanaman pada (Tabel 4) menunjukkan adanya perbedaan tingkat kerusakan tanaman setelah dilakukan aplikasi beberapa perlakuan pestisida nabati. Pemberian limbah kulit biji mete dengan dosis $600 \mathrm{~kg} / \mathrm{ha}$ yang ditaburkan di sekitar tanaman uji menunjukkan 3,56\% tingkatan rating gejala kerusakan tanaman yang terjadi pada hari ke 15 setelah aplikasi. Hasil analisis pada kontrol dan pemberian pestisida nabati limbah tembakau menunjukkan hasil yang tidak berbeda dengan persentase tingkat kerusakan tanaman lebih tinggi dibandingkan perlakuan limbah kulit biji mete dan imidacloprid. Sementara itu pemberian imidakloprid dengan dosis $7,5 \mathrm{~kg} / \mathrm{ha}$ yang ditaburkan di sekitar tanaman uji berpengaruh tidak nyata terhadap rating gejala kerusakan tanaman.

Berdasarkan hasil analisis ragam (Tabel 4) ditunjukkan bahwa perlakuan dari masingmasing pestisida nabati berbeda nyata terhadap rating gejala kerusakan tanaman pada 3 HSA, 6 HSA, 9 HSA, 12 HSA, dan 15 HSA. Pada pengamatan 3 HSA perlakuan menggunakan pestisida nabati limbah kulit biji mete $600 \mathrm{~kg} / \mathrm{ha}$ menunjukkan hasil rata-rata tingkat kerusakan terendah sebesar $1,31 \%$ yang tidak berbeda nyata dengan perlakuan menggunakan limbah tembakau $250 \mathrm{~kg} / \mathrm{ha}$, sedangkan perlakuan menggunakan pestisida nabati limbah tembakau $250 \mathrm{~kg} / \mathrm{ha}$ menunjukkan hasil rata-rata tingkat kerusakan tertinggi sebesar 1,43\%. Imidakloprid adalah insektisida sistemik yang mengganggu transmisi rangsangan di sistem saraf serangga dan mengakibatkan kelumpuhan serangga dan akhirnya kematian. Ini efektif karena imidakloprid bekerja sebagai racun kontak dan lambung (Prabowo, et al 2013).

\section{Rating Gejala Kerusakan Tanaman (Pengujian Secara Tidak Langsung)}

Berdasarkan hasil analisis ragam (Anova) pada pengujian secara tidak langsung menunjukkan bahwa pemberian pestisida nabati yang ditaburkan di sekitar tanaman uji berpengaruh nyata terhadap rating gejala kerusakan tanaman. Pemberian pestisida nabati limbah kulit biji mete berpengaruh nyata terdapat rating gejala kerusakan tanaman pada (4 HSA, 8 HSA, 10 HSA, 12 HSA, dan 14 HSA) namun tidak berbeda nyata pada 2 HSA dengan tingkat kerusakan tanaman sebesar $0 \%$. Meskipun demikian perlakuan pestisida nabati limbah kulit biji mete memiliki potensi lebih baik dari perlakuan pestisida nabati limbah tembakau pada (2 HSA, 4 HSA, 6 HSA, 8 HSA, 10 HSA, 12 HSA, dan 14 HSA) dengan menunjukkan tingkat kerusakan 2,05\% pada 14 HSA.

Berdasarkan data pada (Tabel 5) menunjukkn bahwa pemberian pestisida nabati limbah tembakau dengan dosis $250 \mathrm{~kg} / \mathrm{ha}$ yang ditaburkan di sekitar tanaman uji berpengaruh nyata terhadap rating gejala kerusakan tanaman pada (4 HSA, 6 HSA, 8 HSA, 10 HSA, 12 HSA, dan 14 HSA), namun tidak berbeda nyata pada 2 HSA dengan tingkat kerusakan tanaman mencapai 3, $65 \%$ pada 14 HSA. Sedangkan hasil analisis pada kontrol dan pestisida nabati limbah tembakau menunjukkan tingkat kerusakan yang tidak berbeda nyata dengan persentase tingkat kerusakan tanaman lebih tinggi. Hal ini diduga dalam penggunaan dosis yang rendah limbah tembakau berperan sebagai penstimuli makan terhadap L. stigma. Senyawa bioaktif antifeedant yang terkandung di dalam limbah tembakau kurang mampu mengusir maupun menjerat L. stigma, sehingga aktivitas makan semakin tinggi.Azzam et al.,(2011) menyatakan bahwa aplikasi insektisida berbahan aktif imidakloprid dapat 
mempengaruhi perubahan kandungan hara tanaman di antaranya $\mathrm{Ca}, \mathrm{Cu}, \mathrm{Fe}, \mathrm{Mg}, \mathrm{Mn}, \mathrm{Na}, \mathrm{K}$, dan $\mathrm{Zn}$ yang berimplikasi terhadap ketahanan tanaman terhadap hama tanah.

Tabel 5. Persentase rating gejala kerusakan tanaman pada tahapan pengujian secara langsung

\begin{tabular}{|c|c|c|c|c|c|c|c|c|c|c|c|}
\hline \multirow[t]{2}{*}{ Perlakuan } & \multicolumn{11}{|c|}{ Rating Gejala Kerusakan Tanaman } \\
\hline & 2 HSA & & $4 \mathrm{HSA}$ & & $6 \mathbf{H S}$ & & 8 HSA & & 10 HAS & 12 HSA & 14 HSA \\
\hline Kontrol & 0.15 & $\mathrm{a}$ & 0.45 & $\mathrm{~b}$ & 0.70 & $\mathrm{~b}$ & 1.15 & $\mathrm{~b}$ & $2.95 \mathrm{c}$ & $3.75 \mathrm{c}$ & $4.45 \mathrm{c}$ \\
\hline $\begin{array}{l}\text { LKB Mete } \\
600 \mathrm{~kg} / \mathrm{ha}\end{array}$ & 0.00 & a & 0.10 & $\mathrm{ab}$ & 0.15 & $\mathrm{a}$ & 0.45 & $\mathrm{ab}$ & $1.25 \mathrm{ab}$ & $1.55 \mathrm{ab}$ & $2.05 \mathrm{~b}$ \\
\hline $\begin{array}{l}\text { L. Tembakau } \\
250 \mathrm{~kg} / \mathrm{ha}\end{array}$ & 0.05 & a & 0.20 & $\mathrm{ab}$ & 0.50 & $a b$ & 0.80 & $\mathrm{ab}$ & $1.75 \mathrm{bc}$ & $2.85 \mathrm{bc}$ & $3.65 \mathrm{bc}$ \\
\hline $\begin{array}{l}\text { Imidakloprid } \\
7,5 \mathrm{~kg} / \mathrm{ha}\end{array}$ & 0.00 & a & 0.00 & $\mathrm{a}$ & 0.05 & $\mathrm{a}$ & 0.05 & $\mathrm{a}$ & $0.05 \mathrm{a}$ & $0.05 \mathrm{a}$ & $0.05 \mathrm{a}$ \\
\hline
\end{tabular}

Keterangan: Data telah ditransformasi dengan Archin $\sqrt{x+0,5}$ untuk keperluan analisis statistik. Angka yang diikuti huruf yang sama pada kolom yang sama menunjukkan tidak berbeda nyata pada uji DRMT dengan taraf kesalahan 5\%; HSA: Hari Setelah Aplikasi; LKB: Limbah Kulit Biji, Lb: Limbah.

\section{KESIMPULAN}

Aplikasi pestisida nabati limbah kulit biji mete dengan menaburkan di sekitar tanaman uji tidak berpengaruh terhadap aktivitas antiffedant pada 2 HSA, 4 HSA, 8 HSA, 12 HSA, dan 14 HSA, namun berpengaruh nyata terhadap aktivitas antifeedant L. stigmapada 6 HSA dan 10 HSA. Aplikasi pestisida nabati limbah kulit biji mete pada pengujian secara langsung dengan menaburkan di sekitar tanaman uji tidak mempengaruhi tingkat mortalitas L. stigma, tetapi berpengaruh terhadap rating gejala kerusakan tanaman pada 15 HSA. Pemberian pestisida nabati limbah tembakau menyebabkan mortalitas L. stigma sebesar $1,80 \%$ pada 15 HSA serta memiliki tingkat kerusakan tanaman yang tinggi dibanding dengan perlakuan lainnya. Aplikasi pestisida nabati limbah kulit biji mete pada tahapan pengujian secara tidak langsung dengan menaburkan di sekitar tanaman uji berpengaruh terhadap mortalitas $L$. stigma pada 14 HAS dan pada rating gejala kerusakan tanaman pada 14 HSA. Pemberian pestisida nabati limbah tembakau menyebabkan mortalitas L. stigma sebesar 0,10\% pada 8 HSA dan menunjukkan tidak adanya pengaruh terhadap rating gejala kerusakan tanaman sebesar 3,65\% pada 15 HSA, sedangkan pemberian imidakloprid menyebabkan mortalitas $L$. stigma sebesar $46,87 \%$ pada 6 HSA.

\section{DAFTAR PUSTAKA}

Atmajaya, W.R \& Wahyono, T.E. 2006. Pengaruh Cashew Nut Shell Liquid (CNSL) terhadap Mortalitas Heleopeltis antonii pada Bibit Jambu Mete. Bulletin Littro, 17 Februari. 66-71

Aprilia, Nur Triana. 2011. Studi Pustaka Hama Sengon (Paraserianthes falcataria (L) Nelsen). Skripsi Fakultas Kehutanan IPB Bogor. 
Azzam S, Yang F, Wu JC, Geng J, Yang GQ. 2011. Imidacloprid induced transference effect on some elements in rice plants and the brown planthopper Nilaparvata lugens (Hemiptera: Delphacidae).

Listiyanti, A. Nurkalis, U. Sudiyanti., Hestiningsih R. (2012). Ekstraksi Nikotin Dari Daun Tembakau (Nicotina tabacum) Dan Pemanfaatannya Sebagai Insektisida Nabati Pembunuh Aedes sp. Jurnal ilmiah Mahasiswa, Universitas Diponegoro.

Muzayyinah. 2010. Potensi Ekstrak Limbah Kulit Biji Mete (Anacardium occidentale) Pada Berbagai Pelarut terhadap Daya Tahan Hama Ulat Tanah Penyerang Tanaman Stroberi di Tawangmangu. In Prosiding Seminar Nasional Pendidikan Biologi. Solo, 2010. FKIP-UNS.

Prabowo, H. Dan I. G. A. A. Indrayani. 2013. Lepidiota stigma Fabricius: Uret Pemakan Akar Tanaman Tebu. Infotek Perkebunan Vol. 5 (7): 26.

Saragih, Dora Megawati. 2009. Serangan Uret dan Pengendaliannya Pada Tanaman Eucalyptus hybrid di Hutan Tanaman PT. Toba Pulp Lestarisektor Aek Na Uli Sumantera Utara. Skripsi Fakultas Kehutana IPB, Bogor.

Trubus. 2010. Hama dan Penyakit Tanaman (Deteksi Dini dan Penanggulangannya) Trubus Info Kits. Trubus Swadaya.

Yunita, J., Suprati, N. \& Hidayat, J. 2009. Ekstrak Daun Teklan (Eupatorium riparium) terhadap Mortalitas dan Perkembangan Aedes aegypti. Hioma, 11 (1): $11-17$ 